\title{
LA CONSTRUCCIÓN DE LA AGENDA DE LA JUSTICIA TRANSICIONAL EN CHILE Y LOS GIROS DEL PROBLEMA DE LOS DERECHOS HUMANOS
}

\section{The Chilean transitional justice agenda construction and the twist of the human rights problem}

\author{
CARLA CUBILLOS VEGA \\ Universidad Complutense de Madrid \\ carlacub@ucm.es \\ Cómo citar/Citation \\ Cubillos Vega, C. (2021). \\ La construcción de la agenda de la justicia transicional \\ en Chile y los giros del problema de los derechos humanos. \\ Revista de Estudios Políticos, 194, 65-95. \\ doi: https://doi.org/10.18042/cepc/rep.194.03
}

\section{Resumen}

En el presente trabajo se analizan los giros del proceso por el cual las violaciones de derechos humanos ocurridas en Chile durante la dictadura cívico-militar de 19731990 se fueron construyendo como un problema social que requería una respuesta del Estado. Para ello, se analizan los discursos presentes en el debate sobre la justicia transicional en la arena pública desarrollado en el país a partir de la transición a la democracia, en base al enfoque construccionista social y al modelo de la historia natural de los problemas sociales. El análisis permite entrever las diversas conceptualizaciones que han ido delineando el debate público en torno a las nociones de verdad y justicia y su articulación en las políticas públicas transicionales. Las conclusiones obtenidas apuntan al rol decisivo del movimiento de derechos humanos en la promoción de respuestas alternativas y contribuyen a visibilizar a las víctimas como actores activos en la arena política.

\section{Palabras clave}

Derechos humanos; justicia transicional; problema social; agenda política; Chile. 


\begin{abstract}
This paper analyzes the twists of the construction process of the human rights violation problem, as a social problem, that occurred in Chile during the 1973-1990 civic and military dictatorship, that required a response from the State. For this, we analyze the discourses present in the debate on transitional justice in the public arena, developed in the country from the transition to democracy, based on the social constructionist approach and the model of the natural history of social problems. The analysis allows us to glimpse the various conceptualizations that have been delineating the public debate around the notions of truth and justice and their articulation in transitional public policies. The conclusions point to the decisive role of the human rights movement in promoting alternative responses and contribute to making victims visible as active actors in the political arena.
\end{abstract}

\title{
Keywords
}

Human rights; transitional justice; political agenda; social problem; Chile. 


\section{SUMARIO}

I. INTRODUCCIÓN. II. METODOLOGÍA. III. LA CONSTRUCCIÓN DEL PROBLEMA DE LOS DERECHOS HUMANOS EN CHILE Y SU PUESTA EN AGENDA: 1. El traslado de las demandas a la esfera pública: el movimiento chileno de Derechos Humanos. 2. La legitimación de las demandas y la respuesta del primer Gobierno democrático. 3. El giro frente a la impunidad instituida. 4. La impunidad relativa y las respuestas alternativas. IV. SÍNTESIS. V. CONCLUSIONES. BIBLIOGRAFía.

\section{INTRODUCCIÓN}

Con la vuelta a la democracia en Chile en 1990, luego de diecisiete ańos de dictadura cívico-militar, han surgido y proliferado variados estudios que han abordado diversas dimensiones de las violaciones de derechos humanos ocurridas y su posterior repercusión. A diferencia de aquellas propuestas, las cuales se señalan más adelante, en este trabajo interesa abordar el ámbito de la agenda de las políticas públicas ${ }^{1}$ inscritas en el campo de la justicia transicional (Paige, 2011; Rúa, 2018)². Asimismo, a diferencia de otros estudios,

1 Por agenda se entiende, en este trabajo, un conjunto de asuntos o temas de relevancia social que se han elevado a la arena pública y que las/los gobernantes han identificado, seleccionado y decidido incorporar a sus programas de actuación. En todo caso, como advierte Pautassi (2008) no todos los problemas sociales relevantes se vuelven asuntos públicos, ni estos últimos son considerados en su totalidad por los decisores para incorporarlos a la agenda. En ese sentido, Subirats (1992) identifica tres cuestiones generales que inciden en que un determinado asunto sea incorporado en la agenda política: la valoración del apoyo social que dicho tema tiene, la valoración de su impacto sobre la realidad social y, por último, la viabilidad de una posible solución.

2 La noción de justicia transicional surge a fines del siglo xx; no obstante, a lo largo de la historia podemos hallar numerosos procesos de justicia en el paso de un régimen político a otro; Elster (2004) argumenta que la justicia transicional democrática es casi tan antigua como la democracia misma, no limitándose a los regímenes democráticos modernos, poniendo como ejemplo los episodios de justicia transicional llevados a cabo en decenas de casos a través de la historia y alrededor del mundo, ya sea en contextos de restauración de la monarquía, de independización o de transición de regímenes autocráticos (endógenos o exógenos) a regímenes democráticos. Si bien el concepto, tal y como lo concebimos en la actualidad, tiene entre sus antecedentes más próximos los juicios de Núremberg y Tokio desarrollados tras el término de la Segunda 
este trabajo responde, en cierta medida, a la necesidad observada de visibilizar la organización política y colectiva de quienes han venido siendo considerados como víctimas (Bustamante y Carreño, 2019) y que han influido enormemente en la definición del problema de los derechos humanos e incidido en las políticas, las cuales no han emergido de manera vertical exclusivamente desde el Estado, sino como una construcción social.

En concreto, interesa comprender el proceso mediante el cual se fue gestando la agenda de la justicia transicional como respuesta a un problema social que es enunciado de diversos modos y que se sintetiza en «el problema de los derechos humanos», frase utilizada para englobar las graves violaciones de estos derechos ocurridas durante la dictadura chilena. En suma, el objetivo es analizar el proceso de construcción social del problema de los derechos humanos en Chile y su puesta en agenda. Para ello, es preciso señalar que los mecanismos de la justicia transicional — donde se suelen inscribir tales políticas - son básicamente cuatro: a) justicia penal individual, a través de tribunales nacionales o internacionales, para procesar a los responsables de los crímenes; b) iniciativas para el esclarecimiento de la verdad y de construcción de la memoria histórica, tales como comisiones de verdad $\mathrm{u}$ otras entidades investigadoras, museos, o memoriales, entre otras; c) reparación material y simbólica a las víctimas, y c) reforma de instituciones con el objeto de garantizar la gobernabilidad democrática (Duggan, 2005).

La agenda de las políticas de justicia transicional, como tal, y la inherente construcción social de los problemas que la van configurando, es un ámbito poco o nada abordado. En particular, no se han localizado investigaciones respecto a la construcción de la agenda de la justicia transicional chilena, si bien existe una variedad de estudios relativos a políticas sectoriales (Lira y Piper, 1996; Hails, 2009; Collins, 2013; Madariaga, 2018; Hourcade et al., 2018; Varela y Villasana, 2019). Por su parte, a nivel internacional, es posible encontrar unos pocos estudios sobre la formación de agendas políticas en escenarios de justicia transicional, entre ellos, un análisis relativo a medidas adoptadas en el continente africano (Kagoro, 2012), otro enfocado en la agenda en materia de memoria, verdad y justicia del Gobierno argentino de Macri (Bertoia, 2016)

Guerra Mundial y la ola de procesos judiciales celebrados en Europa durante la década de los setenta (Teitel, 2003; Paige, 2011; Sikkink, 2013), en rigor, el término justicia transicional es empleado por primera vez en la década de los noventa (Paige, 2011). En este trabajo, es este último criterio el que se sigue, dado que se considera que el surgimiento del término se sitúa en un contexto sociopolítico concreto, afectado por una serie de factores que lo dotan de un sentido particular, diferente al que tuvieron las manifestaciones de justicia precedentes. 
y un estudio en que se comparan las agendas políticas de los Gobiernos de Chile y Argentina respecto del problema - y consecuentes políticas - de la memoria (Delgadillo, 2015). Fuera del campo del estudio de las agendas, cabe destacar el trabajo de Ruderer (2010), quien presenta un análisis de la política del pasado desarrollada en Chile desde el retorno de la democracia en 1990 hasta la muerte de Pinochet el año 2006; no obstante, su enfoque epistemológico dista del nuestro ${ }^{3}$. Por último, más en línea con el presente estudio, Collins (2013) concluye que las respuestas frente a las violaciones de derechos humanos cometidas en la dictadura en Chile, en el ámbito de la justicia formal, han surgido en gran medida de las acciones emanadas desde la sociedad civil. Haciendo eco de las conclusiones de Collins (2013), en este trabajo se parte de la premisa de que las agendas no emanan unilateralmente, de manera vertical - y hacia abajo- , de la toma de decisiones de las autoridades públicas, sino que se van construyendo en paralelo a la definición de los problemas a que dan respuesta, en un entramado de intereses y fines en conflicto.

Así, a diferencia de los estudios precedentes, aquí se propone analizar el proceso de construcción social del problema de los derechos humanos y su puesta en agenda recurriendo al enfoque construccionista de los problemas sociales, dada su gran utilidad para este tipo de análisis. Para esta tradición, los problemas sociales no se pueden definir ni comprender a priori, como una condición objetiva, sino a partir de su construcción social en la escena pública. De este modo, como estrategia analítica se acude al modelo metodológico de la historia natural de los problemas (Blumer, 1971; Schneider, 1985; Spector y Kitsuse, 1987; Best, 2002; Loseke y Best, 2003; Best, 2013). Se ha recurrido a esta tradición sociológica poco utilizada por las/los investigadores hispanohablantes (Valcarce, 2005; Moreno y Rodríguez, 2017) porque, sin pretender buscar una explicación causal de la agenda política emanada durante la construcción de los problemas sociales, este enfoque facilita la reconstrucción de la lógica subyacente en la génesis y elaboración de dicha agenda. Si bien el enfoque socioconstructivista ha venido siendo ampliamente utilizado en diversos estudios de casos, donde se ha tenido por objeto analizar determinados problemas sociales, también ha sido igualmente criticado. En concreto, al modelo de la historia natural de los problemas sociales se le ha criticado, por

3 Nuestro enfoque se diferencia porque está situado en el paradigma constructivista, basado concretamente en la teoría sociológica de la construcción de los problemas sociales que es aplicado a diversidad de tópicos, mientras que el enfoque de Ruderer (2010) tiene una perspectiva histórica y se basa en el marco de la política del pasado, un concepto originado en Alemania en la década de los noventa aplicado en concreto a dicho tipo de políticas. 
ejemplo, por conducir a generalizaciones y pronósticos prematuros o seguir un orden lineal que puede resultar engañoso al concentrar las actividades en las primeras etapas y dar en las últimas una falsa sensación de cierre (Schneider, 1985). Pese a las críticas, se opta por esta estrategia porque, aunque no sea perfecta, es la más idónea para alcanzar el objetivo de este trabajo, en tanto permite ofrecer una nueva perspectiva para comprender el fenómeno social abordado, poniendo el foco en los actores sociales que impulsaron la construcción de la agenda política en la materia. No obstante, conscientes de los debates suscitados, se ha intentado evitar tales errores visibilizando la recursividad del modelo.

Los estudios tradicionales sobre la construcción de la agenda política suelen abordar principalmente la cuestión de la selección de problemas (del por qué determinados problemas y no otros) o las relaciones causales o factores que afectan a su construcción; además, suelen poner el énfasis en los medios de comunicación de masas y a considerar la construcción del problema como una etapa que precede al punto cúlmine de la configuración de tal agenda, a saber, la toma de decisiones de las autoridades (Subirats, 1992; Valcarce, 2005; Tamayo y Carrillo, 2005) manifestadas, por ejemplo, en una ley, un programa o un recurso social. Desde el enfoque construccionista, por el contrario, dichas decisiones solo representan una parte fundamental del proceso de configuración del problema social (no de su respuesta última), siendo la expresión de cómo la autoridad interpreta y delimita el problema en la marcha de un ciclo recursivo.

Atendiendo al objetivo propuesto, a continuación, se delinearán los aspectos metodológicos de este estudio. Posteriormente, a la luz del análisis, se irán presentando las diversas actuaciones y debates identificados, las formas en que las partes interesadas formularon sus vindicaciones - reconociendo los principales intereses en juego-, las medidas establecidas por el Estado, las principales críticas a las mismas, los límites y aciertos de tales políticas y las respuestas alternativas.

\section{METODOLOGÍA}

Este trabajo de naturaleza cualitativa se basa en el marco analítico del enfoque construccionista social, según el cual los problemas sociales son definidos colectivamente. Estos problemas se manifiestan en quejas o demandas respecto a determinadas condiciones ante las cuales se esperan ciertas respuestas y en cuyo proceso de configuración, operan intereses, intenciones y objetivos divergentes y conflictivos (Blumer, 1971; Spector y Kitsuse, 1987). Según este marco, todo problema social se configura 
básicamente en dos bloques, el de quienes expresan sus quejas/demandas y el de quienes deben valorar las mismas para otorgar una solución (Loseke y Best, 2003). Dichos bloques son parte de un proceso de definición colectiva en cuyo desarrollo se identifican los problemas sociales, se define cómo se abordan, y se estructura y presenta un plan oficial que luego se ejecuta, y que se irá transformando en el curso de su implementación (Blumer,1971). Este guion da cuenta de que los problemas sociales no son estáticos, sino que se van construyendo en diferentes etapas no lineales. Este modelo ha servido al presente estudio como una guía para comprender e ilustrar cómo la dinámica social, es decir, las demandas de ciertos grupos, los intereses en juego y las respuestas esperadas/proporcionadas por los actores implicados, llevó a la adopción de una agenda de justicia transicional compuesta de unas determinadas políticas públicas.

Diversos autores han aplicado el modelo de historia natural de los problemas sociales a variados estudios de caso, dividiendo el desarrollo de un problema en varios periodos donde concurren distintos actores, hechos/ actividades y dificultades o dilemas (Schneider, 1985; Spector y Kitsuse, 1987; Best, 2002) ${ }^{4}$. En el presente trabajo se siguen las cuatro fases planteadas por Spector y Kitsuse (1987) las que en ningún caso son necesariamente lineales:

a) En la primera fase los sujetos, que pueden ser los propios afectados u otros interlocutores, tienden a manifestar la existencia de un hecho o situación indeseada o dañina, trasladando el asunto desde la esfera privada a la pública.

b) En la segunda fase, una instancia oficial reconoce la legitimidad de las demandas, conduciendo en la mayoría de los casos a investigaciones, propuestas de reforma, o a la creación de organismos oficiales que den respuestas a las situaciones reconocidas. Con ello, se puede transformar la actividad de los sectores demandantes, quienes posiblemente pasen a integrarse en los procedimientos oficiales de respuesta.

4 Blumer alude a cinco etapas: a) emergencia del problema; b) legitimación del problema; c) movilización de la acción con respecto al problema; d) formulación de un plan oficial de acción, y e) implementación del plan (Blumer, 1971); mientras que Best, prevé seis etapas: a) formulación y argumentación de reclamos o demandas; b) cobertura mediática de dicho reclamo, llegando a una mayor audiencia; c) reacción pública a los argumentos emitidos en los reclamos originales y en su difusión mediática, cuyo efecto sería el reconocimiento de la situación por parte de la opinión pública; d) legitimación de la demanda por una instancia oficial con la consecuente elaboración de políticas públicas; e) implementación de tales políticas, y f) reacciones o valoraciones frente a las mismas (Best, 2013). 
c) En la tercera fase vuelven a emerger las demandas y vindicaciones originarias, dado que los sujetos no están satisfechos con las respuestas oficiales.

d) Por último, la cuarta fase implica el rechazo por parte de los demandantes, de las respuestas ofrecidas por la instancia oficial, y el posterior desarrollo de alternativas a las mismas.

En este trabajo el análisis se centra en cómo se construyeron las exigencias o demandas en torno a las violaciones de derechos humanos producidas durante la dictadura chilena y en el modo en que se fueron estableciendo las respuestas por parte del Estado una vez iniciada la transición política, analizando el período donde se llevaron a cabo las principales actuaciones para abordar el problema de los derechos humanos legado de la dictadura 5 .

Respecto a las fuentes consultadas, se recurre al análisis de literatura especializada en la materia proveniente de diversas disciplinas y a datos emanados en la esfera de la opinión pública y del discurso mediático expresado en documentos oficiales, programas de gobierno y discursos presidenciales, declaraciones de agrupaciones de víctimas y personas afectadas, declaraciones e informes de organizaciones no gubernamentales (ONG), así como archivos de prensa publicada durante el período reseñado.

\section{LA CONSTRUCCIÓN DEL PROBLEMA DE LOS DERECHOS HUMANOS EN CHILE Y SU PUESTA EN AGENDA}

\section{EL TRASLADO DE LAS DEMANDAS A LA ESFERA PÚBLICA: EL MOVIMIENTO CHILENO DE DERECHOS HUMANOS}

En la primera fase del modelo de la historia natural los sujetos manifiestan la existencia de una situación indeseada o dañina. Estos sujetos pueden ser los propios afectados como otro tipo de interlocutores, cuyas demandas se trasladan a la esfera pública. En el caso chileno, esta fase se sitúa temporalmente

5 Dicho período de transición política fue inaugurado por el Gobierno de la Concertación de Partidos por la Democracia (la Concertación), que fue una coalición constituida en 1988 con fines políticos y electorales bajo el nombre de Concertación de Partidos por el NO, para derrotar a la dictadura de Pinochet en el plebiscito del 5 de octubre, donde se decidía la continuidad del régimen. La Concertación se integró por dieciséis partidos y agrupaciones políticas opositoras al régimen dictatorial, del sector demócrata cristiano, radical, socialista, socialdemócrata, liberal, de la izquierda cristiana y humanista (BCN, 2010). 
durante la dictadura, donde se empieza a manifestar la existencia del problema de los derechos humanos, y los inicios de la transición a la democracia; sin embargo, las demandas en aquellos períodos van a ser distintas. Durante la dictadura, la demanda se vinculó al cese de las violaciones de derechos humanos, a la aparición de las personas desaparecidas y al retorno de la democracia; las negociaciones fueron, por tanto, distintas y, pese a su indudable interés, sobrepasan el objeto de este trabajo. Posteriormente, iniciada la transición, las demandas se vincularon al objeto de este estudio: la solución del problema en términos de justicia transicional y las políticas a desarrollar en materia de verdad, justicia, reparación y garantías de no repetición. Pese a ser esta segunda variante del problema la que nos interesa, sus primeras manifestaciones coincidieron con las primeras denuncias de violaciones de derechos humanos y demandas sociales expresadas durante dictadura, por lo cual las revisaremos resumidamente.

Durante la dictadura la población, amenazada y perseguida, se encontraba en un estado de indefensión máximo ante las masivas y sistemáticas violaciones de derechos humanos. Estaba imposibilitada, por ello, para expresar su malestar y, sobre todo, para denunciar tales violaciones de manera directa, de ahí que inicialmente fue otro tipo de interlocutores quienes las trasladaron a la esfera pública. Estos interlocutores en un comienzo fueron tan solo las iglesias, que sirvieron tanto de dispositivo de apoyo y de encuentro para las/los familiares de las personas desaparecidas, como de auxilio a las personas perseguidas (Orellana, 1991). En la década de los ochenta el rol de la movilización social adquirió mayor potencia, sumándose al movimiento nuevos actores. Sin embargo, como sucedió con muchas de las organizaciones que conformaron el movimiento de los derechos humanos, unas cesaron sus actividades con el inicio de la democracia en los ańos noventa y las que quedaron se diversificaron, en tanto su compromiso fue atendiendo a intereses diferentes e irreconciliables; así podemos situar los intereses de las agrupaciones de familiares y personas afectadas, frente a los intereses del resto $-\mathrm{O}$ desintereses en tanto se buscaba una salida negociada al problema de los derechos humanos, en pos de la reconciliación-. No obstante, lo importante es destacar que las acciones de este movimiento constituyeron el inicio de la puesta en agenda del problema de los derechos humanos en Chile ${ }^{6}$.

6 Dado que excede el tema abordado en este trabajo y considerando la limitación del espacio, no se pueden señalar exhaustivamente a todas las organizaciones implicadas ni detallar su labor. No obstante, entre las principales podemos destacar el Comité de Cooperación para la paz en Chile (Comité pro Paz o COPACHI), la Fundación de Ayuda Social de las Iglesias Cristianas (FASIC), la Comisión Chilena de Derechos Humanos (CCDH), la Vicaría de la Solidaridad, la Corporación de Promoción y 
Cabe considerar que antes de la dictadura no existía un movimiento de defensa de derechos humanos en el país ${ }^{7}$, sino que este se conformó a propósito de las violaciones de derechos cometidas en el régimen militar ${ }^{8}$ (García, 2011); así, durante los años setenta y hasta inicio de los ochenta, estos organismos fueron multiplicándose y diversificándose, cooperando entre sí durante la dictadura, en la consecución de objetivos comunes (Hutchison, 1991; Orellana, 1991). Todas las organizaciones del movimiento de derechos humanos mantuvieron contacto estrecho con otras organizaciones análogas en el exterior, contando por ello con un importante respaldo internacional, que tuvo su expresión más significativa en la labor de denuncia realizada, reforzada especialmente con la denuncia de chilenas/os en el exilio.

$\mathrm{Si}$ las organizaciones vinculadas a la Iglesia se constituyeron en los actores fundamentales de defensa de los derechos humanos en el terreno de la asistencia social y jurídica y en la defensa ante los tribunales de justicia, las agrupaciones de familiares se erigieron como los principales actores de denuncia.

Defensa de los Derechos del Pueblo (CODEPU), la Fundación de Protección a la Infancia Dañada por los Estados de Emergencia (PIDEE) y el Movimiento Contra la Tortura Sebastián Acevedo (MCTSA). De otro lado, entre las agrupaciones de víctimas: la Asociación de Familiares de Detenidos Desaparecidos (AFDD), la Agrupación de Familiares de Ejecutados Políticos (AFEP), y la Agrupación de Familiares de Presos Políticos (AFPP). Para una cronología y una caracterización más detallada del surgimiento y desarrollo del movimiento de derechos humanos en Chile, se recomienda ver a Orellana (1991).

7 Orellana (1991) señala que en Chile desde 1972 existía el Comité de Defensa de los Derechos Humanos (CODEHS) presidido por Clotario Blest, líder del movimiento sindical; sin embargo, fue una entidad pequeña que dejó de operar en los primeros años de la dictadura.

8 Es importante subrayar que, pese a que el surgimiento de los movimientos de derechos humanos responde a una tendencia internacional, que surgió en nuestra región a partir de la década de los sesenta y que se consolidó en los setenta, sus características difieren según el contexto político y sociocultural. De este modo, el origen del movimiento chileno se distingue de otros movimientos similares surgidos en las dictaduras latinoamericanas, como en Argentina o Uruguay, donde las iglesias no asumieron la defensa de los derechos humanos de la comunidad, o el caso de Brasil, donde dicho apoyo fue tardío y bastante reducido (íd.). Entre esas diversas trayectorias, es destacable el caso de Argentina, donde el movimiento fue inicialmente liderado por las familias de las víctimas, y se conformó fundamentalmente por mujeres — primero las madres y posteriormente las abuelas-. Del mismo modo, en Chile, el liderazgo de las agrupaciones de familiares de víctimas de la represión fue principalmente de mujeres que, cabe añadir, en su mayoría no tenían una trayectoria de militancia política previa. 
La razón de ser de la Asociación de Familiares de Detenidos Desaparecidos (AFDD) fue, desde su creación en 1975, la búsqueda de la verdad; de cada una de las personas desaparecidas bajo la consigna del dónde están, pregunta que alude tanto a la localización de los cuerpos como a los culpables y su responsabilidad (García, 2011). No fue sino hasta 1977 en que las actividades de la AFDD comenzaron a visibilizarse en la sociedad expresando las demandas de la agrupación. Por su parte, la Agrupación de Familiares de Ejecutados Políticos (AFEP), surgió como una rama de la AFDD que, debido a la especificidad de sus demandas (la verdad en torno al establecimiento de responsabilidades y justicia penal para los responsables de las muertes), se constituyó como una agrupación independiente en 1978.

El movimiento de derechos humanos nacido en la dictadura estuvo caracterizado por el pluralismo ideológico y de actuar, donde cada organismo tenía su especificidad, pese a que todos coincidieron en la realización de acciones de denuncia (Orellana, 1991). Solo entre las organizaciones laicas, aunque en menor medida, se desarrolló una labor de movilización social e información que, como bien señala Orellana (1991), repercutieron en la denuncia. Respecto al abordaje del problema de los derechos humanos por parte de estas organizaciones, este autor identifica tres perspectivas: de un lado, la de la Iglesia, principalmente la católica, que interpreta los derechos humanos como derechos de Dios; de otro lado, la de las instituciones laicas donde, a su vez, encontramos dos perspectivas, la de las organizaciones pro derechos humanos y la de las agrupaciones de familiares y víctimas de la represión cuyos principios suscriben a los de la Declaración Universal de los Derechos Humanos, aunque algunas darán un matiz más emancipatorio, ampliando la concepción de derechos de las personas a los derechos del pueblo. De este modo, según sea el abordaje — de la Iglesia desde un iusnaturalismo medieval, o de las entidades laicas, desde un iusnaturalismo ilustrado o desde una perspectiva más social y emancipatoria-, la interpretación del problema adquirirá diferentes matices y, por ende, también las demandas.

En el escenario del plebiscito de 1988 se produjo coincidencia entre el movimiento de derechos humanos y los partidos políticos de oposición al régimen militar (salvo la extrema izquierda) en suscribir la idea de una salida política negociada, la cual debía realizarse con respeto a los derechos humanos, la verdad y la justicia (Orellana, 1991). De este modo, Hutchison (1991) atribuye a este movimiento la presión hacia los partidos de oposición para que en el proceso de transición y las consecuentes negociaciones que este conllevaría, no se negociaran los juicios por violaciones de derechos humanos y, además para que los casos de tortura y desaparecimientos estuviesen presentes en la campaña del plebiscito. Sin embargo, subraya la autora, la decisión de incorporar el tema de los derechos humanos en las posteriores campañas presidenciales ya dependía 
solo de la voluntad política de los propios partidos de oposición al diseñarlas; a partir de ese punto los movimientos de derechos humanos ya no serían tan influyentes.

Se puede concluir que, en esta primera fase de la construcción del problema de los derechos humanos, quienes iniciaron su puesta en agenda fue el recién surgido movimiento de derechos humanos, proporcionando a la población una serie de dispositivos para canalizar sus demandas, a través de la asistencia social, la asistencia legal, la educación popular y, sobre todo, la difusión o denuncia. Asimismo, como afirma Hutchison, a diferencia de otros grupos de derechos humanos análogos de otros países de la región, los grupos chilenos lograron «desarrollar sofisticadas tácticas para influir en el curso de la transición misma» (ibid.: 72). De este modo, fueron estos grupos quienes, al ofrecer una definición razonable del problema, influyeron inicialmente en las decisiones sobre cómo configurar los objetivos y las alternativas de acción de la agenda pública.

\section{LA LEGITIMACIÓN DE LAS DEMANDAS Y LA RESPUESTA DEL PRIMER GOBIERNO DEMOCRÁTICO}

Una vez establecida y difundida una primera definición del problema con sus respectivas demandas, esta debe ser reconocida como legítima, conduciendo a respuestas concretas. En esta segunda fase una instancia oficial debe reconocer la legitimidad de las demandas, conduciendo en la mayoría de los casos a investigaciones, propuestas de reforma, o la creación de organismos oficiales que den respuestas a las situaciones reconocidas. Cuando ello sucede, es posible que la actividad de quienes demandaban las soluciones se transforme, pasando a integrarse en los procedimientos oficiales de respuesta. Esta lógica también se puede identificar en el caso chileno. Las actividades de los principales actores que interpelaron una solución a las violaciones de derechos humanos, el movimiento de derechos humanos, fueron recogidas en el programa de gobierno de la concertación y, posteriormente, cumplidas, aunque «en la medida de lo posible»?.

Para comprender las dificultades que debió sortear este primer Gobierno, es necesaria una breve contextualización. El régimen dictatorial de Pinochet

9 «En la medida de lo posible» es una frase del expresidente chileno Patricio Aylwin que constituyó todo un slogan de su mandato, generando bastante polémica al entenderse como una excusa para no cumplir enérgicamente con la obligación del Gobierno de hacer justicia por las sistemáticas violaciones de derechos humanos cometidas en la dictadura, y como un signo de su debilidad frente a la institucionalidad militar. 
cambió profundamente las bases sociopolíticas de la sociedad chilena en sus diecisiete años de gobierno. A partir de 1990, al nuevo Gobierno democrático se le presentó la colosal tarea de transformar aquel modelo político, cultural y social instaurado, así como de atender a las graves violaciones de derechos humanos cometidas en el pasado. En el programa de gobierno de Patricio Aylwin se abordaron una serie de dimensiones donde era preciso intervenir, con el objeto de cambiar el orden antidemocrático instituido en la dictadura hacia un nuevo modelo; un giro hacia una sociedad democrática y a un Estado de derecho que requería sendos cambios en la institucionalidad. Así, se establecían, por ejemplo, reformas constitucionales y legales para adecuarse al marco internacional de derechos humanos, reformas en el Poder Judicial, reformas en las Fuerzas Armadas (FFAA) y de otras fuerzas del orden y seguridad, y reformas en la Administración. Estas reformas se orientaban a la descentralización del poder, a instaurar una cultura democrática, y a sentar nuevas bases en las políticas económicas, culturales y sociales (Aylwin, 1989). No obstante, muchas de estas aspiraciones programáticas quedaron solamente en un enunciado de intenciones, sin haberse concretado: si bien varias de las propuestas fueron enviadas como proyectos de ley al Parlamento, no progresaron y finalmente acabaron siendo archivados sin siquiera haberse discutido ${ }^{10}$.

Entre todos, quizá el principal obstáculo a dicho cambio de modelo político y social radicó en el mantenimiento de la Constitución ilegítima de Pinochet (de 1980), de la cual en el propio programa de gobierno citado tan solo se contempló una reforma parcial. Esta última apuesta no fue producto de un desliz programático, sino de una serie de negociaciones entre la Concertación de Partidos por la Democracia y el régimen militar, orientadas hacia una transición política consensuada o pactada ${ }^{11}$. Estos acuerdos fueron determinantes

10 Ese es el caso, por ejemplo, de la creación del defensor del pueblo (ombudsman) o del Servicio Nacional de Asistencia Jurídica. Ello debido a que la derecha (como bloque político de oposición) contaba con una representación importante producto del sistema electoral binominal, y especialmente en el Senado, producto de la figura de los senadores designados.

11 En este punto es preciso tener presente que, durante el lapso transcurrido entre el plebiscito de octubre de 1988 y el término oficial del Gobierno militar en marzo de 1990, este procuró dejar «amarrada» toda la política que quería que se desarrollase al inicio de la democracia, lo cual hizo mediante una serie de leyes orgánicas, asegurando así la vigencia de la institucionalidad de Pinochet, incluso si se contase con una minoría parlamentaria. A ello, además, se suma el hecho de que se ofrecieron incentivos para que los jueces de la Corte Suprema se retiraran y, con ello, sustituirlos con nuevos jueces afines a Pinochet: de diecinueve jueces, nueve fueron nombrados por el régimen militar, continuando sus funciones una vez iniciada la democracia. 
en tanto configuraron el escenario de pactos transicionales en diversas materias: económica, militar, institucional y de justicia (Collins, 2013); escenario que, a su vez, influyó en la dinámica de la construcción del problema de los derechos humanos y su incorporación a la agenda de la justicia transicional chilena. En dicho escenario, los consensos entre el nuevo Gobierno democrático y la oposición heredera de la dictadura fueron muy limitados, reduciéndose a cuestiones menores, pues los grandes temas que requerían cambios sustanciales para fundar una democracia plena no alcanzaron acuerdo alguno, como fue el caso de las reformas constitucionales, del cambio de modelo socioeconómico, de la injerencia política del cuerpo militar, o de la solución al problema de los derechos humanos (Garretón, 1994). De ahí que, en esta última materia, pese a que el Gobierno había legitimado el problema enunciado por el movimiento de derechos humanos, las políticas no se orientaron a establecer responsabilidades por las violaciones de derechos humanos ocurridas en la dictadura, sino que se limitaron a desarrollar una agenda verdad en torno al derecho a la vida y a la reconciliación social (Van Boven, 1993; Hourcade et al., 2018).

De acuerdo con Zalaquet (2002) el Gobierno entrante tuvo que tomar en consideración todas estas limitaciones políticas e institucionales, con lo cual, la política para solventar el problema de los derechos humanos debía tener tres objetivos, de un lado, evitar que estos crímenes volvieran a repetirse (lo que requería las reformas arriba aludidas), de otro lado, el establecimiento de la verdad en torno a lo ocurrido y la determinación de responsabilidades y, por último, la reparación a las víctimas y a la sociedad. Entre estas tres cuestiones, la verdad se consideró un valor absoluto e irrenunciable en tanto constituía el pilar para la realización de los otros dos: para prever medidas de reparación y prevención, debe conocerse claramente qué se debe reparar y prevenir (Zalaquett, 1992). Desde dicha perspectiva del establecimiento de la verdad como prioridad, el Gobierno recién asumido comenzó a dialogar con representantes de partidos políticos e integrantes del movimiento de derechos humanos (activistas, familiares de víctimas y líderes religiosos) con el objetivo de definir la política que diese respuesta al problema de los derechos humanos (Hourcade et al., 2018). Fueron varios y diversos los actores interesados en participar de dicho debate y aportar, desde sus posiciones, variadas soluciones. Cabe destacar que, a partir de este período, los debates se caracterizaron por la intervención de tres tipos de actores principales, el Gobierno, los partidos políticos y las FFAA, en tanto los organismos de derechos humanos y agrupaciones de víctimas perdieron en este nuevo escenario el protagonismo que tuvieron en la fase anterior, siendo, en opinión de Collins (2013) marginados porque sus exigencias de justicia fueron consideradas maximalistas e imposibles de satisfacer. Varios de ellos exhortaron a los partidos políticos para que 
apoyasen sus demandas de justicia penal, pero solo recibieron apoyo de aquellos partidos de extrema izquierda, por ser quienes no tenían mucho que ganar — o perder - en el proceso de transición (Hutchison, 1991).

Iniciado el Gobierno democrático, la primera respuesta surgida de los diálogos fue la creación en 1990 de una instancia extrajudicial denominada Comisión de Verdad y Reconciliación (CNVR, o Comisión Rettig) con el mandato de documentar las violaciones de derechos humanos ocurridas durante la dictadura. Coincidimos con Collins (2013) en que esta Comisión resultó no solo ser la principal sino la única iniciativa importante en este período. La lógica de la Comisión fue la siguiente: la verdad se convirtió en un instrumento para satisfacer la justicia, pero no la justicia penal, en tanto esta era opuesta a una convivencia pacífica dado el escenario antes descrito; unas medidas de justicia penal atentarían contra el pacto con las FFAA. La justicia penal era una atribución de los tribunales, debiendo desvincularse así el Gobierno de toda responsabilidad de tomar medidas en ese orden. De hecho, la Comisión tenía que respetar los preceptos de la Constitución política vigente, lo que debía ser verificado por la Contraloría General de la República de Chile (principal entidad fiscalizadora del país), por lo cual no podía tener ningún atisbo de estar conformada como un tribunal (Aylwin, 2006). Por su parte, los tribunales de justicia no tenían en ese escenario mucho margen de actuación, dada la propia configuración heredada del régimen dictatorial y consecuente alineación del Poder Judicial con la ideología e intereses de las FFAA y la extrema derecha (Hilbink, 2014), como por la ley de amnistía de 1978 (que amnistiaba a todas las personas implicadas en delitos cometidos entre el 11 de septiembre de 1973 y el 10 de marzo de 1978), que continuaba vigente.

Siguiendo la lógica de la reconciliación, tampoco era posible esperar resultados de las acciones judiciales, porque estos demoraban y la reconciliación se planteó como algo de suma urgencia. Por ello, como destaca García (2011), se precisó de un mecanismo que permitiese la formación de un concepto colectivo y serio respecto de las graves violaciones de derechos humanos. Este mecanismo lo constituyó la CNVR, integrada por personas consideradas de reconocido prestigio y autoridad moral; para asegurar su legitimidad en toda la sociedad se compuso por ocho miembros, cuatro que habían sido partidarios del régimen militar o del derrocamiento de Allende y cuatro que habían sido defensores de los derechos humanos y opositores del régimen (Zalaquett, 2006). Estos fueron, entonces, los interlocutores válidos para establecer la verdad oficial respecto a lo ocurrido en la dictadura y para marcar las pautas sobre las características que debía tener la política de justicia transicional. El discurso del Informe de la CNVR - Informe Rettig — concentraba la doctrina en materia de derechos humanos del primer Gobierno de la transición (García, 
2011); se priorizó la verdad por sobre la justicia pues el principal objetivo fue lograr la reconciliación y esta última, dado el escenario, era incompatible con la aplicación de la justicia penal, sobre todo, como destaca Zalaquett (2000), cuando los responsables aún tenían importantes cuotas de poder.

El Informe tuvo un enorme impacto en todos los sectores porque supuso una instancia oficial, emanada del Gobierno, donde se reconocía por primera vez que el Estado había violado los derechos humanos; a ello podemos sumar el efecto potenciador que tuvo la cobertura mediática en la prensa escrita que acaparó las portadas y publicó fragmentos del mismo ${ }^{12} 1314$ lo que a su vez fue un contrapeso al hecho de que el Informe íntegro — tres tomos de 450 páginas en promedio, cada uno- no se publicó ni distribuyó libremente de manera masiva como sucedió en el caso de Argentina. La verdad oficial que el Informe instauró tuvo una importancia simbólica tremenda si consideramos que hasta entonces se había negado sistemáticamente la existencia de personas desaparecidas. Además de inaugurar una nueva política de la memoria (Jara, 2020), del Informe emanaron una serie de recomendaciones que, en su mayoría, fueron realizadas a través de diversas políticas sectoriales orientadas a distintos problemas y colectivos, como las personas retornadas del exilio, las familias de personas ejecutadas y detenidas desaparecidas políticas, y al establecimiento de una cultura de la paz y los derechos humanos. Quizá la política más sólida (en perspectiva comparada) fue aquella proclamada a través de la Ley General de Reparaciones, que estableció una serie de beneficios y la creación de la Corporación Nacional de Reparación y Reconciliación (CNRR), encargada de recoger denuncias posteriores al Informe Rettig, calificando los casos en base a los criterios pautados en la Ley y proporcionando, con ello, la posibilidad de ampliar el número de personas beneficiarias que no fueron entrevistadas durante la labor de la CNVR. No obstante, otras de las medidas recomendadas por el Informe no pudieron ser implementadas debido a la relación tensa que persistía entre las FFAA y el Gobierno (Hourcade et al., 2018).

\section{EL GIRO FRENTE A LA IMPUNIDAD INSTITUIDA}

Siguiendo nuestro modelo, en una tercera fase los actores consideran que la respuesta de las instancias oficiales ha sido problemática, por lo que vuelven

12 En «Mensaje al país: 9 Resoluciones anunció S. E. con Informe Rettig». El Mercurio, 05-03-1991, 1.

13 Entregada la verdad sobre violaciones de derechos humanos. La Época, 05-03-1991, 1.

142279 Muertos. La Nación, 05-03-1991, 1. Disponible en: https://doi.org/10.1089/ thy.1991.1.279. 
a emerger las demandas. En el caso chileno, al margen de la apreciación positiva sobre el impacto simbólico del Informe Rettig, cabe señalar que este también fue ampliamente cuestionado, no solo por el movimiento de derechos humanos y partidos políticos de extrema izquierda, sino también por los sectores de la oposición y la institucionalidad militar (Hourcade et al., 2018).

Pinochet y las FFAA cuestionaron la validez histórica y jurídica de los hallazgos, negándose a arrepentirse y a pedir perdón (Fuerzas Armadas y del Orden, 1991) ${ }^{15}$. La Corte Suprema también formuló una respuesta a las críticas que se vertieron sobre su pasividad y permisividad ante la comisión de crímenes durante la dictadura, justificando su actuar en base a las restricciones de sus facultades durante el régimen, negando así cualquier responsabilidad (Corte Suprema de Chile, 1991). Los partidos de oposición al Gobierno de coalición (UDI y RN) dirigieron sus críticas a que el Informe no cubrió los sucesos previos al golpe militar de 1973 y que, en su opinión, explicarían la actuación Militar ${ }^{16}$. Al otro extremo, las agrupaciones de familiares se mostraron decepcionadas, pues esperaban que el Informe provocase un gesto de arrepentimiento por parte de los perpetradores ${ }^{17}$; en concreto, la AFDD cuestionó que se equipararan los delitos de lesa humanidad cometidos por el Estado con aquellos delitos cometidos por organizaciones paramilitares de resistencia a la dictadura, así como también criticaron la ausencia de un listado con los nombres de las personas responsables (García, 2011); igualmente se mostraron insatisfechas con el proyecto de reparación propuesto por el Gobierno (Pereira, 1991). Pese a que fueron invitadas a participar en el primer trámite constitucional de la Cámara de Diputados para discutir el proyecto de la Ley de reparación (Ley 19123) ${ }^{18}$, con posterioridad, tras cuestionarlo, las autoridades resolvieron no continuar con las conversaciones (AFDD, 1991). $\mathrm{Si}$ bien en una primera etapa el primer Gobierno de la Concertación otorgó audiencia a las agrupaciones de familiares y afectados, en lo sucesivo no fue así, marginalizándoles de los espacios donde se decidían las políticas. En tal escenario, la presencia de las agrupaciones en la arena pública —a la luz a la cobertura mediática observada - también fue decreciendo notoriamente.

Con la publicación del Informe Rettig y de la política de reparación, y especialmente tras la declaración por parte del Gobierno, en agosto de 1991,

15 ¿Quién enterró el Informe Rettig? Análisis, 13/19-05-1991, 20-25.

16 Íd.

17 Íd.

18 Junto a representantes de la AFDD, también participaron en la sesión representantes de la AFEP, de la Vicaría de la Solidaridad y de la Comisión Chilena de Derechos Humanos (Cámara de Diputados, 1991). 
de que el proceso de transición democrática había terminado ${ }^{19}$, pareció que se cerraba tácitamente el problema de los derechos humanos. En un seminario privado de la Concertación celebrado en octubre de 1991, las opiniones estaban divididas, mientras para algunos se había avanzado casi nada en la solución al problema, para otros se había hecho bastante sin poner en riesgo la estabilidad del país ${ }^{20}$. De otro lado, el atentado con resultado de muerte en abril de 1991 del entonces senador Jaime Guzmán - exasesor jurídico y político del régimen de Pinochet y artífice de la Constitución política de 1980- contribuyó a que el clima de reconciliación que el Gobierno quería construir, y con ello el propio proceso de transición, se viese gravemente afectado (Rojas, 1991).

A ocho meses de publicado el Informe Rettig, las 211 causas judiciales iniciadas por denuncias de la CNVR por casos de detenidos desaparecidos estaban en estado de sumario, en opinión de la Vicaría, por falta de voluntad de las FFAA para cooperar con el Poder Judicial, aduciendo para ello a razones de seguridad militar (Díaz, 1992). Los parlamentarios más sensibles al tema se lamentaban de que no existían las condiciones propicias para rediscutir la ley de amnistía, por lo que ello sería una pelea perdida; para los sectores defensores de los derechos humanos, no obstante, era necesario revisar la situación de ese decreto ley ya sea por la vía de la derogación o de una reinterpretación, pues se debían cumplir los compromisos de los partidos políticos asumidos con los familiares de los desaparecidos (íd.). Durante este período, principalmente dos sucesos mantuvieron la atención en torno al problema de los derechos humanos: a) el proceso por la querella presentada en 1991 por el monseñor Sergio Valech, por eventuales delitos de inhumación ilegal respecto de personas que permanecerían sepultadas como no identificadas en el Patio 29 del Cementerio General de Santiago, contra quienes resultasen responsables de tales delitos, como quienes eventualmente se pudiesen establecer en el curso de la investigación (Délano, 1991; García, 2011); y b) el juicio al exjefe de la Dirección de Inteligencia Nacional (DINA), Manuel Contreras —en el marco del Caso Letelier ${ }^{21}$ — , que también provocó la atención de los medios en torno a las actuaciones de dicho organismo policial y el paradero de sus agentes. Ambos casos, además del interés mediático, tuvieron especial relevancia como precedentes jurídicos: con el caso del Patio 29 se abrieron una

19 Fin de la Transición. Un asunto de ingeniería política. Análisis, 19/25-08-1991, 5-8.

20 Derechos Humanos. El Gobierno ante el espejo. Análisis, 16/29-09-1991, 22-23.

21 Este caso tuvo como resultado la condena por parte de la Corte Suprema en 1995, al general en retiro Manuel Contreras y a su segundo al mando, el brigadier Pedro Espinoza, en calidad de autores intelectuales del asesinato de Orlando Letelier (BND, 2018). 
serie de posibilidades legales hasta entonces limitadas por la ley de amnistía

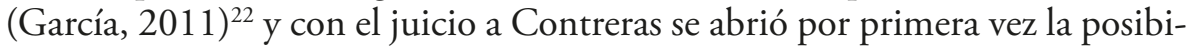
lidad de enjuiciar a los responsables de las violaciones a los derechos humanos durante la dictadura militar.

Las acciones de la AFDD dieron un giro y comenzaron a concentrarse directamente en el ámbito judicial. Como lo declaró Viviana Díaz, presidenta de la AFDD entre 1993 y 2003, en una entrevista concedida a Antonia García (2011), el trabajo de esta organización se volcó al establecimiento del diálogo con partidos políticos y legisladores, con el objeto de anular la ley de amnistía, dado que no habían tenido respuesta de los compromisos establecidos en los programas de gobierno. La presión de las agrupaciones llevó a algunos jueces a investigar los hechos, pero también condujo al malestar de las FFAA y policiales, quienes no tardaron en manifestar su descontento ante las progresivas citaciones a declarar de sus miembros, exigiendo que terminen las investigaciones (Camus, 1993); exigencia que tuvo su punto cúlmine en 1993 con el «boinazo», cuando el edificio de las FFAA, ubicado frente a la sede presidencial del Gobierno, fue rodeado de militares vestidos con uniformes de combate (Camus, 1993; Soto, 2016). Este suceso puso en evidencia que la transición no había terminado y que decretar su fin había sido un error, el cual fue reconocido por el presidente Aylwin (Donoso, 1993), pero también condujo a que se empezara a discutir entre el Gobierno y las FFAA, la posibilidad de agilizar las investigaciones que implicasen a miembros activos de las mismas (García, 2011). Con estos hechos, como advierte García (2011) se produjo un cambio de interlocutores: desde las organizaciones de derechos humanos a los militares, quienes pasaron a ser los destinatarios principales de las futuras propuestas políticas. El presidente Aylwin admitió la importancia de los intereses de los militares y la disposición del Gobierno a buscar una salida judicial a los procesos de derechos humanos, con el objeto de que los militares volviesen a sus cuarteles y con ello también la estabilidad política. Los militares tenían el poder de desestabilizar el Gobierno, por lo que se debía evitar su malestar. Se cristalizaba, con ello, la política de la verdad como impunidad donde la justicia fue canjeada por la paz.

El Gobierno no pudo ofrecer soluciones satisfactorias para ambas partes, FFAA y víctimas/familiares, pues sus demandas eran incompatibles. Para estos

22 En aquel momento la desaparición no era un delito en Chile, por lo cual el aludir al delito de la exhumación, que sí estaba contemplado en el Código Penal, permitía establecer justicia por las desapariciones mediante otra vía, la de la inhumación ilegal y clandestina y, eventualmente, la del homicidio — hasta entonces presunto- (García, 2011). 
últimos lo que importaba era determinar los hechos, no de manera general, como ya se había establecido en el Informe de la CNVR, sino de manera individual, caso a caso, es decir, encontrar los cuerpos y castigar a los responsables. Para las FFAA, el interés se situaba en mantener el honor de la institución, la impunidad y los privilegios. Sumado a estos dos bloques, las presiones también emanaban de sectores de la propia Concertación, en particular de la DC, quienes no querían que el problema de los derechos humanos pasase al próximo Gobierno de Eduardo Frei (Donoso, 1993). A meses para las próximas elecciones presidenciales, el Gobierno presentó un proyecto de ley ante el Congreso, dirigido al sobreseimiento de aquellos casos en que apareciesen los cuerpos. La iniciativa fue recibida con esperanza por todos los sectores; para los militares era una oportunidad de que terminasen los juicios y se diese por cerrado el irritante capítulo de los derechos humanos; para los familiares de las víctimas, agrupaciones de derechos humanos y dirigentes políticos afines, representaba una de las últimas oportunidades de acceder a la verdad, pues entendían que el tema de los derechos humanos ya estaba entrando en su etapa final, dado que eran muchas las presiones por «dar vuelta la hoja y poner fin a la transición $»^{23}$. El proyecto, no obstante, no prosperó en la votación por diversos motivos emanados de todos los sectores; en suma, de una parte, que no daba garantías suficientes a los militares, de otra, que la propuesta era incompleta e incluso que consagraba la impunidad velada (Otano, 1993; García, 2011).

La sensación de impunidad por parte de las víctimas de violaciones de derechos humanos al final del primer Gobierno democrático, no obstante, no se refiere solo al sentido legal, también se refiere al statu quo: cuando Pinochet seguía en un cargo de poder como comandante en jefe del Ejército, cuando sus afines constituían una mayoría parlamentaria debido a los senadores designados, y cuando las reformas al Poder Judicial, a las instituciones del orden y la seguridad y a la propia Constitución redactada en dictadura y que configura el escenario político, no habían sido posibles.

\section{LA IMPUNIDAD RELATIVA Y LAS RESPUESTAS ALTERNATIVAS}

En la fase anterior, las demandas de los familiares no fueron satisfechas. Dichas demandas exigían decisiones políticas orientadas a cambiar la estructura institucional heredada de la dictadura, el principal obstáculo para la justicia, y esas decisiones no fueron tomadas, instaurándose así una política de

23 La difícil respuesta. Agencia de Prensa de Servicios Internacionales, 12/25-07-1993, 13-14. 
impunidad fundada en el conocimiento de la verdad. Como señala Schneider (1985), la principal característica en esta cuarta fase es que, en vista de la incapacidad del sistema, los sectores demandantes desarrollan dispositivos alternativos para generar respuestas afines a sus intereses. De este modo, ante el rechazo hacia dicha política, no tardaron en surgir respuestas alternativas centradas principalmente en dos ámbitos, la justicia y la memoria. No obstante, ello no significa que desde la institucionalidad no surgieran otras respuestas pues, como se ha indicado, este modelo no es forzosamente lineal, por tanto, a continuación, se revisarán aquellas respuestas — que sin embargo fueron bastantes débiles-, junto con las respuestas alternativas que surgieron de los sectores demandantes.

Dado que la noción de justicia es compleja y suele suceder que nunca cumple con los ideales de quienes la exigen, que a su vez creen firmemente en ella, las víctimas acaban desilusionándose de las instituciones e incluso pueden sentirse traicionadas (Sikkink, 2013). De acuerdo con García (2011), tras sentirse defraudados por las respuestas obtenidas, lo único que quedó a los familiares fue la memoria, que fue utilizada tanto como un instrumento para homenajear a las víctimas, así como para dotarse de instancias desde donde ejercer la acción política, por ejemplo, en torno a los memoriales. No obstante, coincidimos con Collins (2013) en que las agrupaciones de familiares tuvieron un rol aún más relevante en la generación de dispositivos alternativos para responder a sus demandas insatisfechas de justicia, el cual fue precisamente por la vía de los recursos legales. Asimismo, Jara (2020) también ha destacado, entre diversas acciones, aquellas prácticas de justicia alternativas a la justicia penal, denominadas funas ${ }^{24}$.

Al periodo anterior se sucedieron muy pocos avances orientados a la resolución del problema por parte de las instancias oficiales, pudiéndose destacar el informe de la Corporación Nacional de Reparación y Reconciliación (Informe de Calificación de Víctimas de Violaciones de derechos humanos y de la Violencia Política, de 1996). Si la verdad fue el hilo conductor del Gobierno de Aylwin, la reconciliación lo fue en el Gobierno sucesivo de Frei. La diferencia con el Gobierno anterior es que, como señala García (2011), aquí por primera vez la reconciliación se relacionó con las divisiones entre el mundo militar y el civil, divisiones del pasado que perduraban en el presente y que eran resultado de decisiones políticas. Se reconoció así públicamente que el tema de los derechos humanos aún estaba inconcluso; y con ello,

24 La palabra funa proviene de la lengua mapudungun, donde alude a algo que está podrido o en mal estado. Consiste en un acto público de repudio o escarmiento contra una persona, pudiendo desarrollarse mediante diversas actuaciones. 
que la reconciliación estaba inconclusa, que la democracia era imperfecta y que las políticas debían orientarse a la reforma de las instituciones. Bajo esa nueva apuesta política, Frei presentó un nuevo proyecto relativo a los casos de derechos humanos, considerando solo los casos cubiertos por la ley de amnistía, lo que significaba que una vez que estos fuesen resueltos, es decir, que aparecieran los cuerpos y se determinaran los responsables, tales casos serían sobreseídos, renunciándose explícitamente a la justicia penal. Nuevamente surgió el enfrentamiento con las instituciones militares, dada la alusión a una reforma institucional; así como con la AFDD, en tanto este proyecto atentaba contra sus demandas de justicia penal. Conocer la verdad ya no era suficiente, para ellos; exigían que se respetase el Estado de Derecho y que se obtuviese una reparación jurídica. Como el proyecto de Aylwin, este tampoco prosperó.

En 1998 se comenzaron a dar una serie de cambios políticos y jurídicos en el país, que tuvieron como colofón la orden de arresto a Pinochet por el delito de tortura, promovida en octubre de ese año por el juez español Baltazar Garzón, quien se amparó en la doctrina de la jurisdicción universal. Estos hechos fueron el cimiento para que en las décadas siguientes el problema de los derechos humanos cobrara nuevo impulso; como señala Collins (2013) se abrieron cientos de procesos judiciales, se conformó una nueva comisión de verdad en la cual se amplió la nómina de personas reconocidas como víctimas (Informe Valech I de 2005) y se recuperaron y rehabilitaron los que fueron sitios clandestinos de represión y tortura durante la dictadura, emplazándose como lugares de defensa y promoción de los derechos humanos. Estos avances, subraya Collins fueron producto de una «confluencia de presiones desde actores no estatales, domésticos y externos» (ibid.: 88) que incidieron notablemente en el sistema de justicia. Como señala la autora, 1998 fue un ańo clave: en enero se admitió la primera querella criminal particular contra Pinochet por su participación en delitos de lesa humanidad, presentada por la entonces presidenta del Partido Comunista Gladys Marín y el abogado Eduardo Contreras; a esta querella se sumó pronto la presentada por familiares de víctimas por el caso caravana de la muerte. Ambas querellas fueron acogidas a tramitación. Por su parte, la Corte Suprema dictó un fallo decisivo, al aceptar el argumento legal de que se debían investigar las desapariciones sin que la ley de amnistía supusiera un obstáculo (ibid.) ${ }^{25}$. Ese año, además, Pinochet había asumido cono senador vitalicio, por tanto, al dejar el mando en el Ejército fue más factible promover acciones legales en su contra (Zalaquett, 2000). Tras su

25 Fallo de la Corte Suprema Rol 469-1998, del 9 de septiembre de 1998 sobre el caso Pedro Poblete Cordova. 
detención en Londres, el Gobierno de Frei asumió una postura de defensa, aludiendo a la soberanía nacional y al derecho de desarrollar una transición libremente sin la injerencia internacional.

En este escenario, en 1999 se propuso la polémica Mesa de Diálogo de Derechos Humanos, con el objeto de determinar el paradero de las personas desaparecidas durante la dictadura, aunque nuevamente sin interferir con la función de los tribunales (id.). De una parte, la Mesa fue interpretada como una muestra interesada de la buena voluntad del Gobierno de atender las violaciones de derechos humanos cometidas en el pasado, garantizando ante la comunidad internacional que Chile estaba preparado para juzgar a Pinochet de manera autónoma, obteniendo con ello su liberación y retorno al país. De otra parte, en un momento en que la labor de abogados y defensores de derechos humanos estaba generando resultados judiciales satisfactorios, esto se interpretó como una desviación o distractor del objetivo de justicia penal (Hiner, 2009; García, 2011), por ello las agrupaciones de familiares de víctimas (AFDD y AEFP) se negaron a participar. Cabe destacar que con la Mesa se reunieron por primera vez las FFAA y del orden, representantes de organizaciones de derechos humanos y del mundo religioso y profesionales (abogados, psicólogos e historiadores), para esclarecer los hechos, e igualmente por primera vez, las FFAA reconocieron la existencia de personas desaparecidas, emitiendo una declaración de nunca más (Miranda y Matus, 2018). Este giro de actitud responde a que los intereses de la institución militar habían variado, en gran medida por el recambio generacional (Zalaquett, 2000) y porque Pinochet estaba fuera del juego público tras su deslegitimación por su arresto (García, 2011; Collins, 2013). Si bien la mesa estaba programada para concluir su labor al término del mandato del presidente Frei en marzo del 2000, debido a una serie de percances esta se extendió hasta inicios del mandato del presidente Lagos, quien a mediados del 2000 dio a conocer sus resultados, los cuales nuevamente no fueron los esperados, pues no se entregó información relevante ni veraz sobre las personas desaparecidas, por lo que las agrupaciones de familiares se sintieron engañadas (Miranda y Matus, 2018).

Hacia el año 2000, ya en pleno mandato de Lagos, otra demanda surge en la escena pública. Tanto el Informe de la CNVR como la política derivada del mismo, habían excluido a las personas presas políticas como sujetos de derechos reparatorios. Durante los años precedentes la respuesta a las demandas e incluso el foco mediático se había centrado de manera exclusiva en las víctimas con resultado de muerte y en las personas detenidas desaparecidas cuya muerte era presunta. Se ignoró a las personas sobrevivientes que fueron presas políticas y torturadas, quienes, alentadas por las nuevas querellas surgidas a partir de 1998 empezaron a agruparse para visibilizar sus esfuerzos por recuperar sitios clandestinos de detención y tortura, dar a conocer su 
experiencia y exigir medidas de reparación (Collins, 2013; Hourcade et al., 2018). Estas nuevas agrupaciones de ex presas/os políticos no solo se avocaron a la recuperación de sitios de memoria y a exigir reparaciones sociales como víctimas, sino que también tuvieron un rol muy activo en la interposición de querellas criminales por el delito de tortura. La respuesta oficial a sus demandas fue la creación de una segunda Comisión de Verdad el año 2003, denominada Comisión Valech en referencia al nombre de su presidente, enmarcada en la política del Gobierno de Lagos para solventar el problema de derechos humanos pendiente en su mandato (CEP, 2003; Hourcade et al., 2018). Dicha comisión tenía el objetivo de identificar aquellas personas que habían sido privadas de libertad y torturadas por motivos políticos, concluyendo su labor con un Informe (Informe Valech I, publicado en 2005) donde se reconocieron cerca de 30000 víctimas, se identificaron 1132 recintos de detención y se formularon una serie de recomendaciones para adoptar medidas de reparación (Hourcade et al., 2018) ${ }^{26}$.

Concluimos, en sintonía con Collins (2013), en que el balance de avances en materia de justicia fue "el resultado de presiones desde la sociedad civil e inesperadas “irrupciones de la memoria”, más que de una política oficial sistemática de repudio a la violencia política y atención al manejo de su legado» (p. 79), a lo cual se suma el hecho de que la detención de Pinochet en 1998 permitió ampliar el camino a la justicia penal doméstica, aun cuando, como destaca Nash (2016), el enjuiciamiento de los victimarios siga siendo en la actualidad el principal desafío en dicho ámbito. Además, a la interposición de querellas judiciales y a la recuperación de sitios de memoria, se sumaron otras prácticas de justicia alternativa que es necesario reconocer, entre las que destacan las funas. Como señala Jara (2020), las funas son un tipo de sanción social colectiva e informal, que funciona en paralelo a la sanción jurídica o institucional. Se trata de un ritual público donde integrantes de organizaciones sociales, familiares de víctimas y personas simpatizantes se reúnen fuera de la casa o trabajo de personas que fueron colaboradoras del régimen militar y cuya participación en crímenes de lesa humanidad aun continua impune, para difundir su identidad y denunciar sus actos. De acuerdo con la autora, constituyen una práctica marginal que ha venido "disputando en el nivel micropolítico el problema de la legitimación» (Jara, 2020: 260) de las narrativas (y a nuestro juicio también de las respuestas) oficiales.

26 En 2015, durante el segundo Gobierno de Bachelet, se entregó una indemnización de carácter reparatorio cuyo antecedente fue la huelga de hambre realizada por expresos políticos/as en distintas ciudades del país, exigiendo igualdad en los beneficios respecto de otras categorías de víctimas de la dictadura (Ovalle, 2015; Hourcade et al., 2018). 


\section{SÍNTESIS}

El problema de los derechos humanos originado de la política represiva de la dictadura se fue enunciando de diferentes modos en función de los escenarios y actores, agrupando bajo la denominación global de derechos humanos a un conjunto de diversos asuntos que inciden en este ámbito. Como se ha visto, en consonancia con la interpretación de la justicia transicional como campo (Rua, 2018), el enunciado del problema de los derechos humanos en la postdictadura tiene, de manera bien general, diferentes significados dependiendo del modo en que se apropia del discurso de las violaciones de derechos humanos cada actor y lo formula desde su perspectiva/posición y atendiendo a sus intereses (Bourdieu y Wacquant, 2005):

- Para el propio Gobierno de coalición, la Iglesia católica y los grupos políticos de oposición, el problema es, básicamente, el de la verdad global como instrumento para el fin último de la reconciliación social.

- Para las víctimas, coincidiendo con algunas organizaciones de derechos humanos y profesionales que se desempeñan en el campo de la justicia transicional, en un primer momento es el problema de la justicia asociado a la verdad particular (de cada caso individual) y la consecuente aparición de las personas detenidas desaparecidas o de sus cuerpos. Sin embargo, este problema luego se irá transformando en el problema de la justicia ante la impunidad; en el caso de las personas detenidas desaparecidas, ya no se espera solo que aparezcan sus cuerpos, sino sobre todo saber qué les sucedió, conocer a los responsables y que a estos se les aplique la justicia penal por tales crímenes. Las mismas responsabilidades y sanciones se exigen en el caso de las personas ejecutadas políticas y de las personas sobrevivientes que fueron torturadas. En la actualidad, no obstante, las demandas de justicia penal de los familiares de detenidos desaparecidos nuevamente han dejado de ser prioritarias centrándose, como lo fue en un inicio, en la verdad de lo ocurrido pues «simplemente, la gente no se quiere morir sin saber dónde están, o sin tener la mínima noción de qué pasó con quienes han buscado casi toda su vida» (Miranda y Matus, 2018: 8).

- Para las FFAA y del orden, en cambio, hasta finales de los ańos noventa no se admitía tal problema; desde su perspectiva, no se habían cometido violaciones de derechos humanos, sino que, de un lado, había ocurrido una guerra con sus inherentes consecuencias y, de otro, en dicho contexto pudieron darse casos de abusos como hechos aislados, atribuibles a individuos que actuaron al margen de la institucionalidad. 
En Chile, el ejército permaneció unido en torno a la figura de Pinochet y no fue sino hasta el año 2000, cuando esta institución admitió públicamente la ocurrencia de tales crímenes de lesa humanidad, tras la celebración de la Mesa de Diálogo, coincidiendo con la previa deslegitimación de la figura del exdictador tras el caso Pinochet. En este nuevo contexto, sin embargo, el problema remitió igualmente a la verdad como vía para la reconciliación social.

\section{CONCLUSIONES}

En este trabajo se ha revisado cómo se fue construyendo la agenda de justicia transicional en Chile, analizando e identificando, en dicho proceso, las lógicas, discursos y hechos que lo fueron sustentando, ofreciendo, más allá de la intuición y el sentido común, una trama fundamentada.

Bajo el enfoque del construccionismo social de los problemas sociales, aunque cualquier fenómeno social pueda ser un tema potencial para interpelar políticas, se pone el foco en los sectores demandantes, quienes configuran el sentido público respecto de cuál es el problema; es decir, estos sectores lo definen. En los párrafos precedentes hemos visto cómo el problema de los derechos humanos en Chile fue definido en un primer momento por el movimiento de derechos humanos y cómo, en las décadas posteriores, fueron principalmente estas mismas agrupaciones, con sus nuevas incorporaciones y relevos generacionales, quienes continuaron dotándolo de sentido, pugnando con los intentos de cierre que los diversos Gobiernos procuraron dar al problema a través de políticas públicas orientadas a la verdad como instrumento para la reconciliación social. El modelo de justicia transicional adoptado en nuestro país se caracterizó, en términos muy generales, por la priorización de la paz y la reconciliación, en desmedro de la justicia. No obstante, tampoco podemos obviar que estas soluciones se dieron en un contexto político extremadamente complejo.

Sumándonos a algunas de las conclusiones de estudios precedentes comentados en nuestra introducción, en este trabajo se ha querido visibilizar la dimensión política de los sectores demandantes, extrayendo el conflicto de la dimensión privada, donde tradicionalmente ha sido emplazado. En dicha lógica es el Estado el que se ha responsabilizado por los crímenes cometidos y - como un símbolo de honor - ha pedido perdón en nombre de unos victimarios anonimizados, otorgando de manera vertical y descendente unas determinadas soluciones a quienes considera víctimas. Aquí hemos podido apreciar una construcción diferente del problema de los derechos humanos por cada actor según sus prioridades. Quienes vieron la solución a las violaciones de los 
derechos humanos como el problema de las desapariciones y de la impunidad; quienes, como un problema de reconciliación y quienes, incluso, lo negaron durante décadas. Para los primeros, no podía haber reconciliación sin justicia (ni perdón ni olvido), para los segundos, la prioridad era la reconciliación pues solo con ella se alcanzaría la unidad nacional. Las respuestas oficiales que emanaron del Gobierno, no obstante, solo beneficiaron parcialmente a algunos actores y las exigencias de justicia nunca fueron respondidas como una política de Estado. Sin un marco jurídico garante del derecho a la reparación, que evitara la impunidad, era muy difícil esperar una justicia de transición exitosa.

Por último, los resultados de este trabajo también permiten reflexionar respecto de los mecanismos del paradigma clásico de justicia transicional que, sin duda, son insuficientes, sobre todo cuando, entre sus medidas, no se considera el abordaje de reformas sociales e institucionales. También cuando no se atiende a la desigualdad estructural que sustenta el conflicto. Al margen de las exigencias de justicia penal (que se deberían dar por sentado ante un crimen de lesa humanidad), otros problemas en la sociedad chilena también han contribuido a mantener abiertas las heridas de la dictadura: problemas que afectaron no solo a las víctimas consideradas directas, sino a toda la sociedad en su conjunto, poniendo sobre la mesa la discusión sobre el alcance que deberían tener las medidas de justicia en transiciones de sociedades postconflicto, de cara a mantener la paz social. Entre tales problemas se destacan la marginación y la polarización social instituidas con las políticas neoliberales que fueron consagradas por el régimen militar en su Constitución política de 1980, que han eclosionado el pasado 18 de octubre un potente estallido social que ha operado bajo una nueva demanda de «dignidad» que, a su vez, aglutina una serie de demandas de derechos humanos, principalmente económicos, sociales y ambientales. Asimismo, este fenómeno reciente ha dejado patente que la política del nunca más o de no repetición fue un fracaso, pues en dicho marco de movilizaciones y protestas, se han vuelto a producir graves y sistemáticas violaciones de derechos humanos, atentándose contra la vida y la integridad física y mental de miles de ciudadanos/as.

\section{Bibliografía}

Agrupación de Familiares de Detenidos Desaparecidos (AFDD) (1991). Carta de Agrupación de Familiares de Detenidos Desaparecidos al Presidente Patricio Aylwin. Disponible en: https://bit.ly/2WGqRsf.

Aylwin, A. (2006). Secretos del Informe Rettig. Megavisión, 03-03-2006. Disponible en: https://bit.ly/2Yj1fCR.

Aylwin, P. (1989). Programa de Gobierno Concertación de Partidos por la Democracia. Santiago: Editora Jurídica Publiley. 
Biblioteca del Congreso Nacional de Chile (BCN) (2010). Partidos, movimientos y coaliciones. Concertación de Partidos por la Democracia [web]. Disponible en: https://bit.ly/2WFyGym.

Biblioteca Nacional Digital de Chile (BND) (2018). Orlando Letelier del Solar (1932-1976). Atentado terrorista. Memoria Chilena [web]. Disponible en: https://bit.ly/3BgvQz8.

Bertoia, L. (2016). La agenda de Memoria, Verdad y Justicia en tiempos de cambios. Tensiones, rupturas y continuidades en el discurso del gobierno macrista en torno al terrorismo de Estado. Aletheia, 7 (13), 1-18.

Best, J. (2002). Constructing the Sociology of Social Problems: Spector and Kitsuse Twenty-Five Years Later. Sociological Forum, 17 (4), 699-706. Disponible en: https://doi. org/10.1023/A:1021037709754.

Best, J. (2013). Social problems. New York; London: W.W. Norton and Company.

Blumer, H. (1971). Social problems as collective behavior. Social Problems, 18 (3), 298-306. Disponible en: https://doi.org/10.2307/799797.

Bourdieu, P. y Wacquant, L. (2005). Una invitación a la sociología reflexiva. Buenos Aires: Siglo XXI Editores.

Bustamante, J. y Careño, A. (2019). Reparación simbólica, trauma y victimización: la respuesta del Estado chileno a las violaciones de Derechos Humanos (1973-1990). Íconos, Revista de Ciencias Sociales, 67 (24), 39-59. Disponible en: https://doi.org/10.17141/iconos. 67.2020.4231.

Cámara de Diputados (1991). Primer informe de la Comisión de Derechos Humanos, Nacionalidad y Ciudadanía sobre el Proyecto de Ley que establece diversas normas de reparación para los familiares de las víctimas a que se refiere el Informe de la Comisión Nacional de Verdad y Reconciliación. Boletín, 316-06-1. Disponible en: https://bit.ly/2YjJB1N.

Camus, M. (1993). Las razones de un «boinazo». Agencia de Prensa de Servicios Internacionales, 31-05-1993.

Centro de Estudios Públicos (CEP) (2003). Propuesta de Derechos Humanos del Gobierno del presidente Ricardo Lagos. Estudios Públicos, 92, 313-333.

Collins, C. (2013). Chile a más de dos décadas de justicia de transición. Revista de Ciencia Politica, 51 (2), 79-113. Disponible en: https://doi.org/10.5354/0716-1077.2013.30160.

Corte Suprema de Chile (1991). Respuesta de la Corte Suprema al Informe de la Comisión Nacional de Verdad y Reconciliación. Estudios Públicos, 42. Disponible en: https://bit. ly/2Yl9JIV.

Délano, M. (1991). Descansen en paz las víctimas de Pinochet. Los jueces deberán pronunciarse sobre el hallazgo de cadáveres de desaparecidos. El País, 16-09-1991. Disponible en: https://bit.ly/2Yonwig.

Delgadillo, J. (2015). Los tiempos de la memoria en las agendas politicas de Argentina y Chile. Buenos Aires: Eudeba.

Díaz, G. (1992). Informe Rettig. Una verdad sin sanción penal. Análisis, 25-12-1991 a 05-011992, 26-29.

Donoso, J. (1993). Gobierno de Aylwin. Asignaturas pendientes. Agencia de Prensa de Servicios Internacionales, 28-06-1993 a 11-07-1993, 18-21.

Duggan, C. (2005). Prólogo. En A. Rettberg (comp.). Entre el perdón y el paredón: preguntas y dilemas de la justicia transicional (pp. 7-12). Bogotá: Ediciones Uniandes; Canadá e International Development Research Centre. 
Elster, J. (2004). Closing the books. Transitional Justice in Historical Perspective. Cambridge: Cambridge University Press. Disponible en: https://doi.org/10.1017/CBO97805116 07011.

Fuerzas Armadas y del Orden (1991). Respuestas de las Fuerzas Armadas y de Orden al Informe de la Comisión Nacional de Verdad y Reconciliación. Estudios Públicos, 41. Disponible en: https://bit.ly/3izhhiK.

García, A. (2011). La muerte lenta de los desaparecidos en Chile. Santiago: Cuarto Propio.

Garretón, M. (1994). Transición incompleta y régimen consolidado. Las paradojas de la democratización chilena. Revista de Ciencia Política, 16 (1-2), 21-32.

Hails K. (2009). Las secuelas psicológicas y las necesidades en salud mental para las víctimas de la dictadura: una mirada critica a los servicios de PRAIS. Independent Study Project (ISP) Collection. Disponible en: https://bit.ly/3mjfnDW.

Hilbink, L. (2014). Jueces y politica en democracia y dictadura. Lecciones desde Chile. México, DF: Facultad Latinoamericana de Ciencias Sociales.

Hiner, H. (2009). Voces soterradas, violencias ignoradas: discurso, violencia política y género en los Informes Rettig y Valech. Latin American Research Review, 44 (3), 50-74. Disponible en: https://doi.org/10.1353/lar.0.0082.

Hourcade, S., Ghelfi, F., Palmás, L. y Perelman, M. (2018). Comisiones de la Verdad de Chile: verdad y reparaciones como politica de Estado (Informe CMI, 14). Bergen: Christian Michelsen Institut.

Hutchison, E. (1991). El movimiento de derechos humanos en Chile bajo el régimen autoritario, 1973-1988. En P. Orellana y E. Hutchison. El movimiento de derechos humanos en Chile, 1973-1990 (pp. 69-142). Santiago: Centro de Estudios Políticos Latinoamericanos Simón Bolívar.

Jara, D. (2020). Las Comisiones de Verdad, sus narrativas y efectos en el largo plazo: disputas en torno a la representación de los perpetradores en la posdictadura chilena. Atenea, 521, 249-264. Disponible en: https://doi.org/10.29393/At521-17CVDJ10017.

Kagoro, B. (2012). The paradox of alien knowledge, narrative and praxis: Transitional justice and the politics of agenda setting in Africa. En M. Chrispus (ed.). Where Law Meets Reality: Forging African Transitional Justice (pp. 4-52). Cape Town: Pambazuka Press.

Lira, E. y Piper, I. (1996). Reparación, Derechos humanos y salud mental. Santiago: ILAS; Ediciones Chile América CESOC.

Loseke, D. y Best, J. (2003). Social Problems. Constructionist Readings. New York: Aldine de Gruyter.

Madariaga, C. (2018). El trauma social como problema de salud pública en Chile. ¿Es «reparable» la reparación? Revista Chilena de Salud Pública, 22 (1), 75-86. Disponible en: https://doi.org/10.5354/0719-5281.2018.51045.

Miranda, B. y Matus, A. (2018). El ocaso de la AFDD. The Clinic, 01-07-2018. Disponible en: https://bit.ly/3a6jZYr.

Moreno, A. y Rodríguez, T. (2017). Joel Best y la construcción de problemas sociales. En J. Ramírez y A. Morquecho (coords.) Repensar a los teóricos de la sociedad III (pp. 71-89). Jalisco: Universidad de Guadalajara.

Nash, C. (2016). La transición chilena y justicia transicional. Análisis crítico. Revista Derecho y Sociedad, 47, 129-144. 
Orellana, P. (1991). Los organismos de derechos humanos en Chile hacia 1985. En P. Orellana y E. Hutchison. El movimiento de derechos humanos en Chile, 1973-1990 (pp. 9-68). Santiago: Centro de Estudios Políticos Latinoamericanos Simón Bolívar.

Otano, R. (1993). La hora de las verdades. Familiares, Townley, Ley Aylwin. Agencia de Prensa de Servicios Internacionales, 25-08-1993 a 05-09-1993, 15-17.

Ovalle, F. (2015). Las historias de vida que llevaron a los presos políticos a iniciar una riesgosa huelga de hambre. BioBio Chile, 30-05-2015. Disponible en: https://bit. $1 y / 3$ ovB06N.

Paige, A. (2011). Cómo las «transiciones» reconfiguraron los derechos humanos: una historia conceptual de la justicia transicional. En F. Reátegui (ed.). Justicia transicional: manual para América Latina (pp. 73-134). Brasil: Ministerio de Justicia, Comisión de Amnistía y Centro Internacional para la Justicia transicional.

Pautassi, L. (2008). La articulación entre políticas públicas y derechos. En V. Abramovich, X. Erazo y J. Orbe (eds.). Políticas públicas para un Estado social de derechos (pp. 89-116). Santiago, Chile: LOM Ediciones.

Pereira, P. (1991). El Gobierno optó por la confrontación. Análisis, 01/07-04-1991, 11.

Rojas, P. (1991). Asesinato de Jaime Guzmán. Una herida a la Transición. Análisis, 08/14-041991, 14-15.

Rúa, C. (2018). El campo de la justicia transicional. Universum, 33 (1), 187-210. Disponible en: https://doi.org/10.4067/S0718-23762018000100187.

Ruderer, S. (2010). La política del pasado en Chile 1990-2006: ¿Un modelo chileno? Universum, 25 (2), 161-177. Disponible en: https://doi.org/10.4067/S0718-237620 10000200010 .

Schneider, J. (1985). Social problems theory: The constructionist view. Annual Review of Sociology, 11 (1), 209-229. Disponible en: https://doi.org/10.1146/annurev.so.11.080 185.001233 .

Sikkink, K. (2013). La cascada de la justicia. Cómo los juicios de lesa humanidad están cambiando el mundo en politica. Buenos Aires: Gedisa.

Soto, C. (2016). «El boinazo»: el momento más tenso del gobierno de Patricio Aylwin. La Tercera. Disponible en: https://bit.ly/3uUCKaZ.

Spector, M. y Kitsuse, J. (1987). Constructing Social Problems. New York: Routledge.

Subirats, J. (1992). Análisis de politicas públicas y eficacia de la Administración. Madrid: Ministerio para las Administraciones Publicas.

Tamayo, M. y Carrillo, E. (2005). La formación de la agenda pública. Foro Internacional, 65 (4), 658-681.

Teitel, R. (2003). Transitional Justice Genealogy. Harvard Human Rights Journal, 16, 69-94.

Valcarce, F. (2005). La sociología de los problemas públicos. Una perspectiva crítica para el estudio de las relaciones entre la sociedad y la política. Nómadas. Critical Journal of Social and Juridical Sciences, 12, 2. Disponible en: https://bit.ly/3a5CtrU.

Van Boven, T. (1993). Estudio relativo al derecho de restitución, indemnización y rehabilitación a las victimas de violaciones flagrantes de los derechos humanos y las libertades fundamentales (Informe definitivo presentado por el Sr. Theo Van Boven, Relator Especial, EE/CN.4I Sub.2/1993/8, 2 de julio de 1993). Ginebra: Comisión de Derechos Humanos, Naciones Unidas. 
Varela, A. y Villasana, P. (2019). Aproximación crítica al sentido de la reparación en salud en población sobreviviente de violencia política en Chile. Salud de los Trabajadores, 27 (1), 93-104.

Zalaquett, J. (1992). Balancing Ethical Imperatives and Political Constraints: The Dilemma of New Democracies Confronting Past Human Rights Violations. Hastings Law Journal, 43, 1428-1429.

(2000). La Mesa de Diálogo sobre derechos humanos y el proceso de transición política en Chile. Estudios Públicos, 79, 5-30.

(2002). Introduction to the English Edition by José Zalaquett (Report of the Chilean National Commission on Truth and Reconciliation). Indiana: United States Institute of Peace. Disponible en: https://bit.ly/3Bc1KNa.

(2006). Secretos del informe Rettig. Megavisión, 03-06-2006. Disponible en: https:// bit.ly/3oAoa7m. 
